\title{
Commentary on recent guidelines for treating hypertension
}

Wilbert S. Aronow

Cardiology Division, Department of Medicine, Westchester Medical Center/New York Medical College, Valhalla, New York, USA

Submitted: 8 June 2014

Accepted: 15 June 2014

Arch Med Sci 2014; 10, 6: 1069-1072

DOI: 10.5114/aoms.2014.47818

Copyright @ 2014 Termedia \& Banach

The American College of Cardiology Foundation/American Heart Association 2011 expert consensus document on hypertension in the elderly recommended a blood pressure $<140 / 90 \mathrm{~mm} \mathrm{Hg}$ in adults younger than 80 years of age at high risk for cardiovascular events [1]. On the basis of data from the Hypertension in the Very Elderly Trial [2], these guidelines state that the systolic blood pressure (SBP) should be reduced to 140$145 \mathrm{~mm} \mathrm{Hg}$ if tolerated in adults aged 80 years and older [1]. I concur with these guidelines [3-7].

The Systolic Hypertension in the Elderly Program (SHEP) also showed reduction in cardiovascular events in elderly patients including those older than 80 years whose SBP was reduced to $140-145 \mathrm{~mm} \mathrm{Hg}$ by antihypertensive drug therapy [8]. The choice of specific antihypertensive drugs such as diuretics, angiotensin-converting enzyme (ACE) inhibitors, angiotensin receptor blockers (ARBs), $\beta$-blockers, or calcium channel blockers (CCBs) depends on efficacy, tolerability, presence of specific comorbidities and cost [1]. If $\beta$-blockers are used, I would not use atenolol [9-12] but would use carvedilol, nebivolol, or bisoprolol [11, 12]. $\beta$-Blockers should be especially used in patients with hypertension and ischemic heart disease. The current place of use of $\beta$-blockers in treatment of hypertension is extensively discussed elsewhere [11, 12].

A meta-analysis of 147 randomized trials including 464,000 persons with hypertension showed that except for the extra protective effect of $\beta$-blockers given after myocardial infarction and a minor additional effect of CCBs in preventing stroke, the use of $\beta$-blockers, ACE inhibitors, ARBs, diuretics, and CCBs causes a similar decrease in coronary events and stroke for a given decrease in blood pressure $[13,14]$. The proportionate reduction in cardiovascular events was the same or similar regardless of pretreatment blood pressure and the presence or absence of cardiovascular events [13, 14].

The European Society of Hypertension/European Society of Cardiology 2013 guidelines recommend lowering the SBP to $<140 \mathrm{~mm} \mathrm{Hg}$ in patients at low to moderate cardiovascular risk, diabetics, and patients with prior stroke or transient ischemic attack, coronary heart disease, or chronic kidney disease (CKD) [15]. In older patients younger than 80 years with SBP $\geq 160 \mathrm{~mm} \mathrm{Hg}$, the SBP should be lowered to 140$150 \mathrm{~mm} \mathrm{Hg}$ with consideration of SBP < $140 \mathrm{~mm} \mathrm{Hg}$. In patients older than 80 years with SBP $\geq 160 \mathrm{~mm} \mathrm{Hg}$, the SBP should be lowered to 140$150 \mathrm{~mm} \mathrm{Hg}$ provided they are in good physical and mental condition [15].
Corresponding author: Wilbert S. Aronow MD, FACC, FAHA

Cardiology Division New York Medical College Macy Pavilion, Room 138 Valhalla, NY 10595, USA Phone: (914) 493-5311 Fax: (914) 235-6274 E-mail:wsaronow@aol.com 
The American Diabetes Society 2013 guidelines recommend that diabetics with hypertension should have their SBP lowered to $<140 \mathrm{~mm} \mathrm{Hg}$ [16]. Systolic blood pressure of $<130 \mathrm{~mm} \mathrm{Hg}$ may be considered in younger patients with long life expectancy if achieved with few drugs and without side effects. The 2012 International Society of Nephrology guidelines for treatment of blood pressure in patients with non-dialysis-dependent CKD recommend that adults with CKD without diabetes mellitus [17] or with diabetes mellitus [18] with hypertension and albuminuria < $30 \mathrm{mg}$ per $24 \mathrm{~h}$ should have their blood pressure lowered to $\leq 140 / \leq 90 \mathrm{~mm} \mathrm{Hg}$ with a class I B indication. If albuminuria greater than $30 \mathrm{mg} /$ day is present, lowering of the blood pressure to $\leq 130 / \leq 80 \mathrm{~mm} \mathrm{Hg}$ has a class II $D$ indication which I would not follow $[17,18]$.

The 2014 guidelines report from the Eighth Joint National Committee (JNC 8) on management of high blood pressure in adults made 9 recommendations [19]. The first recommendation was to use antihypertensive drug therapy in patients aged 60 years and older without CKD or diabetes mellitus to lower the SBP to $<150 \mathrm{~mm} \mathrm{Hg}$ and the diastolic blood pressure (DBP) to $<90 \mathrm{~mm} \mathrm{Hg}$ [19]. I agree with the diastolic blood pressure goal but disagree with the SBP goal recommendation, as do a minority report from JNC 8 and the American College of Cardiology Foundation/American Heart Association 2011 expert consensus document on hypertension in the elderly, which recommend that the SBP goal in patients younger than 80 years with hypertension without CKD or diabetes mellitus should be $<140 \mathrm{~mm} \mathrm{Hg}[1,20]$.

The Reasons for Geographic and Racial Differences in Stroke (REGARDS) study is an observational study of risk factors for stroke which includes 4,181 patients aged 55 to 64 years, 3,767 patients aged 65 to 74 years, and 1,839 patients aged 75 years and older (mean age: 79.3 years) [21-23]. Median follow-up was 4.5 years for first occurrence of a coronary heart disease or stroke event, 4.5 years for nonfatal myocardial infarction or coronary heart disease death, 5.7 years for stroke, and 6.0 years for all-cause mortality. The data from this study generated a hypothesis that for all patients older than 55 years, the SBP should be lower than $140 \mathrm{~mm} \mathrm{Hg}$, with optimal values possibly between 120 and $139 \mathrm{~mm} \mathrm{Hg}$ [21, 22]. The data from this study also suggest that the lowest risk for stroke at a median follow-up of 5.7 years occurs with SBP $<140 \mathrm{~mm} \mathrm{Hg}$ in patients aged 55 to 64 years old, $<130 \mathrm{~mm} \mathrm{Hg}$ in patients aged 65 to 74 years old, and $<150 \mathrm{~mm} \mathrm{Hg}$ for patients aged 75 years and older [23].

Elderly persons have the lowest rates of adequate blood pressure control and the highest inci- dence of cardiovascular events. Blood pressure is adequately controlled in $36 \%$ of men and $28 \%$ of women between ages $60-79$ years and in 38\% of men and $23 \%$ of women aged 80 years and older [24]. I am very concerned that the higher SBP goal in older persons recommended by JNC 8 will lead to a higher incidence of cardiovascular events and mortality.

The second recommendation from JNC 8 was to use antihypertensive drug therapy to treat adults younger than 60 years to lower the DBP goal to $<90 \mathrm{~mm} \mathrm{Hg}$ [19]. I concur with these guidelines.

The third recommendation from JNC 8 was to use antihypertensive drug therapy to lower the SBP goal to $<140 \mathrm{~mm} \mathrm{Hg}$ in adults younger than 60 years [19]. I concur with these guidelines.

The fourth recommendation from JNC 8 was to use antihypertensive drug therapy to lower the blood pressure to $<140 / 90 \mathrm{~mm} \mathrm{Hg}$ in adults aged 18 years and older with CKD [19]. I concur with these guidelines.

The fifth recommendation from JNC 8 was to use antihypertensive drug therapy to lower the blood pressure to $<140 / 90 \mathrm{~mm} \mathrm{Hg}$ in adults aged 18 years and older with diabetes mellitus [19]. I concur with these guidelines.

The sixth recommendation from JNC 8 in the general nonblack population including diabetics was to use as initial antihypertensive therapy a thiazide-type diuretic, CCB, ACE inhibitor, or ARB [19]. I would use $\beta$-blockers as discussed elsewhere $[11,12]$. $\beta$-Blockers should be especially used in patients with hypertension and ischemic heart disease [1, 11-14]. The choice of specific antihypertensive drugs used depends on efficacy, tolerability, presence of associated comorbidities, and cost [1].

The seventh recommendation from JNC 8 in the general black population including diabetics was to use as initial antihypertensive therapy a thiazide-type diuretic or CCB [19]. The choice of specific antihypertensive drugs used depends on efficacy, tolerability, presence of associated comorbidities, and cost [1].

The eighth recommendation from JNC 8 states that in adults aged 18 years and older with CKD, initial or add-on antihypertensive drug therapy should include an ACE inhibitor or ARB to improve renal outcomes [19]. This includes all patients with hypertension and CKD regardless of race and presence or absence of diabetes mellitus. I agree with this recommendation. Compared with amlodipine, ramipril reduced progression of CKD in African-Americans with hypertensive nephrosclerosis without diabetes mellitus and an estimated glomerular filtration rate between 20 and $65 \mathrm{ml} /$ $\mathrm{min} / 1.73 \mathrm{~m}^{2}$ [25].

The ninth recommendation from JNC 8 states that the main goal of antihypertensive drug treat- 
ment is to achieve and maintain the blood pressure goal [10]. I concur. If the goal blood pressure is not achieved in 1 month, increase the dose of the initial antihypertensive drug or add a second drug from one of the classes of drug listed in recommendation 6 . This list should also include a $\beta$-blocker. If the goal blood pressure is still not achieved, add a third class of drug. Do not use an ACE inhibitor plus an ARB together as you will not increase efficacy but will increase adverse effects [26]. If a fourth antihypertensive drug is needed, I would use an aldosterone antagonist. Referral to a specialist in hypertension may be necessary if the goal blood pressure cannot be achieved.

A 2013 blood pressure update is discussed elsewhere [22]. I also concur with the recommendations from the following 4 papers [27-30].

The European Society of Hypertension position paper summarizes current evidence, unmet needs, and practical recommendations on use of renal sympathetic denervation to treat resistant hypertension in hypertension excellence centers [31]. However, the Symplicity HTN-3 study showed in 535 patients with resistant hypertension randomized to renal sympathetic denervation using a Medtronic Symplicity catheter system or to a sham control group that renal sympathetic denervation was not better than a sham-control arm in reducing office SBP at 6 months or 24-hour ambulatory SBP at 6 months [32].

\section{References}

1. Aronow WS, Fleg JL, Pepine CJ, et al. ACCF/AHA 2011 expert consensus document on hypertension in the elderly: a report of the American College of Cardiology Foundation Task Force on Clinical Expert Consensus Documents. Developed in collaboration with the American Academy of Neurology, American Geriatrics Society, American Society for Preventive Cardiology, American Society of Hypertension, American Society of Nephrology, Association of Black Cardiologists, and European Society of Hypertension. J Am Coll Cardiol 2011; 57: 2037-114.

2. Beckett NS, Peters R, Fletcher AE, et al. Treatment of hypertension in patients 80 years of age or older. $\mathrm{N}$ Engl J Med 2008; 358: 1887-98.

3. Banach M, Aronow WS. Should we have any doubts about hypertension therapy in elderly patients? ACCF/ AHA 2011 expert consensus document on hypertension in the elderly. Pol Arch Med Wewn 2011; 121: 253-8.

4. Aronow WS, Banach M. Ten most important things to learn from the ACCF/AHA 2011 expert consensus document on hypertension in the elderly. Blood Press 2012; 21: 3-5.

5. Aronow WS. What should the optimal blood pressure goal be in patients with diabetes mellitus or chronic kidney disease? Arch Med Sci 2012; 8: 399-402.

6. Banach M, Aronow WS. Blood pressure j-curve: current concepts. Curr Hypertens Rep 2012; 14: 556-66.

7. Banach M, Aronow WS. Hypertension therapy in the older adults-do we know the answers to all the questions? The status after publication of the ACCFAHA expert con- sensus document on hypertension in the elderly. J Hum Hypertens 2012; 26: 641-3.

8. SHEP Cooperative Research Group. Prevention of stroke by antihypertensive drug treatment in older persons with isolated systolic hypertension. Final results of the Systolic Hypertension in the Elderly Program (SHEP). JAMA 1991; 265: 3255-64.

9. Aronow WS. Might losartan reduce sudden cardiac death in diabetic patients with hypertension? Lancet 2003; 362: 591-2.

10. Carlberg B, Samuelsson O, Lindholm LH. Atenolol in hypertension: is it a wise choice? Lancet 2004; 364: 1684-9.

11. Aronow WS. Current role of beta-blockers in the treatment of hypertension. Expert Opin Pharmacother 2010; 11: 2599-607.

12. Bielecka-Dabrowa A, Aronow WS, Rysz J, Banach M. Current place of beta blockers in the treatment of hypertension. Curr Vasc Pharnacol 2010; 8: 733-41.

13. Mancia G, Laurent S, Agabiti-Rosei E, et al. Reappraisal of European guidelines on hypertension management: a European Society of Hypertension Task Force document. Blood Press 2009; 18: 308-47.

14. Law MR, Morris JK, Wald NJ. Use of BP lowering drugs in the prevention of cardiovascular disease: meta-analysis of 147 randomised trials in the context of expectations from prospective epidemiological studies. BMJ 2009; 338: b1665.

15. Mancia G, Fagard R, Narkiewicz K, et al. 2013 ESH/ESC guidelines for the management of arterial hypertension: the Task Force for the Management of Arterial Hypertension of the European Society of Hypertension (ESH) and of the European Society of Cardiology (ESC). Eur Heart J 2013; 34: 2159-219.

16. American Diabetes Association. Position statement. Standards of Medical Care in Diabetes-2013. Diabetes Care 2013; 36 (Suppl. 1): S11-66.

17. KDIGO Clinical Practice Guideline for the Management of Blood Pressure in Chronic Kidney Disease. Chapter 3. Blood pressure management in CKD ND patients without diabetes mellitus. Kidney Int Suppl. 2012; 2: 357-62.

18. KDIGO Clinical Practice Guideline for the Management of Blood Pressure in Chronic Kidney Disease. Chapter 4. Blood pressure management in CKD ND patients with diabetes mellitus. Kidney Int Suppl. 2012; 2: 363-9.

19. James PA, Oparil S, Carter BL, et al. 2014 evidence-based guideline for the management of high blood pressure in adults. Report From the Panel Members Appointed to the Eighth Joint National Committee (JNC 8). JAMA 2014; 311: 507-20.

20. Wright JT Jr, Fine LJ, Lackland DT, et al. Evidence supporting a systolic blood pressure goal of less than $150 \mathrm{~mm}$ $\mathrm{Hg}$ in patients aged 60 years or older: the minority view. Ann Intern Med 2014; 160: 499-503.

21. Banach M, Bromfield S, Howard G, et al. Association of systolic blood pressure levels with cardiovascular events and all-cause mortality among older adults taking antihypertensive medication. Int J Cardiol 2014; 176: 219-26.

22. Banach M, Serban C, Aronow WS, et al. Lipid, blood pressure and kidney update 2013. Int Urol Nephrol 2014; 46: 947-61.

23. Banach M, Bromfield S, Howard G, et al. What are the blood pressure levels associated with the lowest stroke rates in the elderly? findings from the Reasons for Geographic and Racial differences in stroke (REGARDS) cohort study. Stroke 2014; 44 (Suppl.): ATPM99. 
24. Lloyd-Jones DM, Evans JC, Levy D. Hypertension in adults across the age spectrum: current outcomes and control in the community. JAMA 2005; 294: 466-72.

25. Agodoa LY, Appel L, Bakris GL, et al. Effect of ramipril vs amlodipine on renal outcomes in hypertensive nephrosclerosis. A randomized controlled trial. JAMA 2001; 285: 2719-28.

26. Yusuf S, Teo KK, Pogue J, et al. Telmisartan, ramipril, or both in patients at high risk for vascular events. N Engl J Med 2008; 358: 1547-59.

27. Malyszko J, Muntner P, Rysz J, Banach M. Blood pressure levels and stroke: J-curve phenomenon. Curr Hypertens Rep 2013; 15: 575-81.

28. Banach M, Michalska M, Kjeldsen SE, et al. What should be the optimal levels of blood pressure: does the J-curve phenomenon really exist? Expert Opin Pharmacother 2011; 12: 1835-44.

29. Krzysztoszek J, Wierzejska E, Paczkowska A, Ratajczak P. Health related behaviours and hypertension prevention in Poland. An environmental study. Arch Med Sci 2013; 9: 218-29.

30. Chiquete E, Ocho-Guzman A, Vargas-Sanchez A, et al. Blood pressure at hospital admission and outcome after primary intracerebral hemorrhage. Arch Med Sci 2013; 9: 34-9.

31. Schmieder RE, Redon J, Grassi G, et al. ESH position paper: renal denervation: an interventional therapy of resistant hypertension. J Hypertens 2012; 30: 837-41.

32. Bhatt DL, Kandzari DE, O'Neill WW, et al. A controlled trial of renal denervation for resistant hypertension. N Engl J Med 2014; 370: 393-401. 